OPEN ACCESS

Edited by:

Junji Xing,

Houston Methodist Research Institute, United States

Reviewed by:

Humberto Lanz-Mendoza, National Institute of Public Health

(Mexico), Mexico

Chaojie Wang,

Oregon Health and Science University, United States

${ }^{*}$ Correspondence:

Kyoko Tsukiyama-Kohara kkohara@vet.kagoshima-u.ac.jp

Specialty section

This article was submitted to Virology,

a section of the journal

Frontiers in Microbiology

Received: 20 July 2021

Accepted: 23 August 2021

Published: 16 September 2021

Citation:

Kayesh MEH, Kohara M and Tsukiyama-Kohara K (2021) Recent Insights Into the Molecular Mechanism of Toll-Like Receptor Response to Dengue Virus Infection.

Front. Microbiol. 12:744233. doi: 10.3389/fmicb.2021.744233

\section{Recent Insights Into the Molecular Mechanism of Toll-Like Receptor Response to Dengue Virus Infection}

\author{
Mohammad Enamul Hoque Kayesh ${ }^{1,2}$, Michinori Kohara $^{3}$ and \\ Kyoko Tsukiyama-Kohara ${ }^{1 *}$ \\ 1 Transboundary Animal Diseases Centre, Joint Faculty of Veterinary Medicine, Kagoshima University, Kagoshima, Japan, \\ ${ }^{2}$ Department of Microbiology and Public Health, Faculty of Animal Science and Veterinary Medicine, Patuakhali Science \\ and Technology University, Barishal, Bangladesh, ${ }^{3}$ Department of Microbiology and Cell Biology, Tokyo Metropolitan Institute \\ of Medical Science, Tokyo, Japan
}

Dengue is the most prevalent and rapidly spreading mosquito-borne viral disease caused by dengue virus (DENV). Recently, DENV has been affecting humans within an expanding geographic range due to the warming of the earth. Innate immune responses play a significant role in antiviral defense, and Toll-like receptors (TLRs) are key regulators of innate immunity. Therefore, a detailed understanding of TLR and DENV interactions is important for devising therapeutic and preventive strategies. Several studies have indicated the ability of DENV to modulate the TLR signaling pathway and host immune response. Vaccination is considered one of the most successful medical interventions for preventing viral infections. However, only a partially protective dengue vaccine, the first licensed dengue vaccine CYD-TDV, is available in some dengue-endemic countries to protect against DENV infection. Therefore, the development of a fully protective, durable, and safe DENV vaccine is a priority for global health. Here, we demonstrate the progress made in our understanding of the host response to DENV infection, with a particular focus on TLR response and how DENV avoids the response toward establishing infection. We also discuss dengue vaccine candidates in late-stage development and the issues that must be overcome to enable their success.

Keywords: innate immune response, Toll-like receptors, dengue virus, infection, vaccine

\section{INTRODUCTION}

Dengue is the most important arthropod-borne human viral infection caused by dengue virus (DENV); it is a global health concern in many tropical and subtropical countries and areas, and most outbreaks occur in urban and semi-urban areas (Guzman et al., 2010; World Health Organization (WHO), 2020). Aedes aegypti is the primary vector for DENV transmission, while Aedes albopictus is a less common vector (Lambrechts et al., 2010). DENV is a positive-sense, single-stranded RNA virus with a genome of $10.7 \mathrm{~kb}$ under the family Flaviviridae and the genus Flavivirus (Kuhn et al., 2002). The DENV genome encodes three structural proteins, the capsid (C), membrane (M), and envelope (E), and seven non-structural proteins (NS1, NS2A, NS2B, NS3, NS4A, NS4B, and NS5) (Kuhn et al., 2002; Guzman et al., 2010). DENV has four genetically and 
antigenically distinct serotypes: DENV-1, DENV-2, DENV-3, and DENV-4 (Simmons et al., 2012). While protection against homologous reinfection is lifelong, only short-term protection can be provided against heterologous infection (Gibbons et al., 2007; Aguas et al., 2019). Moreover, heterologous infection may cause severe dengue, possibly because of the antibody-dependent enhancement (ADE) effect (Dejnirattisai et al., 2010; Katzelnick et al., 2017). DENV infection causes a spectrum of illness in humans, ranging from asymptomatic to mild fever, as well as potentially life-threatening severe dengue such as dengue hemorrhagic fever (DHF) and dengue shock syndrome (DSS; Harris et al., 2000). Severe dengue is characterized by plasma leakage, hemorrhagic tendencies, organ failure, shock, and death (Srikiatkhachorn, 2009). However, the mechanisms underlying dengue-related diseases are not completely understood. It has been reported that innate immunity plays a pivotal role during early DENV infection stages in both priming protection and disease induction (Costa et al., 2013). Type I interferons (IFNs) are important for host defense against viral infections; during infection, viruses are recognized by different pattern recognition receptors (PRRs), including Toll-like receptors (TLRs), retinoic acid-inducible gene I (RIG-I)-like receptors (RLRs), and nucleotide-binding oligomerization domain-like receptors [NOD-like receptors (NLRs)]. This recognition may lead to the induction of the genes encoding type I IFNs through several distinct signaling pathways (Kawai and Akira, 2011; McNab et al., 2015).

According to a recent estimate, approximately 390 million DENV infections occur annually worldwide, and 3.9 billion people are at risk of acquiring infections (Bhatt et al., 2013). During the last two decades, there has been a significant increase in the incidence of dengue, which has risen from 505,430 cases in 2000 to over $2,400,138$ and 3,312,040 cases in 2010 and 2015, respectively (World Health Organization (WHO), 2020). The number of deaths also increased from 960 to over 4,032 between 2000 and 2015, emphasizing the urgent need for a safe and effective dengue vaccine (World Health Organization (WHO), 2020). The global rise in dengue is influenced by several factors, including climate change, population growth, high population density, unplanned rapid urbanization and construction, absence of reliable piped water, and ineffective vector control strategies (Wilder-Smith et al., 2010; Simmons et al., 2012; Struchiner et al., 2015). Moreover, the rapid global spread of dengue is associated with human mobility through air travel (Tian et al., 2017). Vector control strategies should assist with controlling dengue infection (Kittayapong et al., 2017; Ritchie, 2018); however, vaccines may provide the best intervention from the perspectives of both public health and economic concerns (Wilder-Smith, 2020). The first dengue vaccine, chimeric yellow fever 17D-tetravalent dengue vaccine (CYD-TDV)/Dengvaxia, was developed by Sanofi Pasteur Co., and licensed in 2015 (Hadinegoro et al., 2015). This vaccine is now only recommended for use in seropositive individuals. However, there are currently no effective prophylactic and/or therapeutic pan-serotype DENV vaccines (Tremblay et al., 2019). Vaccines that can provide long-term protection against each of the four DENV serotypes by inducing neutralizing antibodies
(nAbs) are essential for controlling the disease and the avoidance of ADE-mediated severe dengue (Murphy and Whitehead, 2011). Here, we discuss the current progress in our understanding of the host innate immune response to DENV infection, particularly the TLR response and its evasion/inhibition by DENV to establish infection. We also discuss dengue vaccine candidates in the late stages of development, highlighting the challenges that must be overcome regarding these candidate vaccines.

\section{INNATE IMMUNE RESPONSE TO DENV INFECTION}

A complex series of events are involved in the interactions between a virus and the host immune system that determine the outcome of an infection (Kayesh et al., 2019). The innate immune response is a key component of the host defense system and acts as the first line of immune defense against many viral infections (Zuniga et al., 2015). However, the innate immune response may not always be protective; it may also contribute to pathology, particularly when the response is uncontrolled (Modhiran et al., 2015). TLR signaling is involved in the regulation of both proand anti-inflammatory cytokines, linking early innate immune responses and adaptive immunity (Ozato et al., 2002). Moreover, cytokines show multifaceted interactions and regulate immune responses, which may induce disease pathogenesis (Sanapala and Pola, 2020). Notably, TLR activation may act as a doubleedged sword, and it is possible to enhance immune-mediated pathologies instead of inducing an immune response to protect against pathogens (Salaun et al., 2007; Huang et al., 2008; Yokota et al., 2010). Therefore, a complete understanding of the innate immune response induced by DENV infection is essential for understanding DENV pathogenesis and its effective control and prophylactic measures. Here, we discuss the innate immune response against DENV infection, with a particular focus on TLR response. For further information on the innate immune response to DENV infection, there are some previously published reviews that could provide more wide information (NavarroSanchez et al., 2005; Mathew, 2018; Rathore and St John, 2018; Uno and Ross, 2018; King et al., 2020; Malavige et al., 2020).

\section{TLR RESPONSE TO DENV INFECTION}

The pathogenesis of dengue is complex, and its underlying mechanisms are not fully understood. The clinical outcome of DENV infection depends on the complex interplay between the virus and host immune response (Costa et al., 2013; Yacoub et al., 2013). TLRs play a crucial role in innate immunity against viral infections and can activate NF- $\kappa \mathrm{B}$, a critical transcriptional factor (Rahman and McFadden, 2011). A previous study showed that Fc $\gamma$ RI and Fc $\gamma$ RIIa synergistically facilitate the entry of DENV antibody complexes into THP-1 (human monocytic cell line) cells, and an interplay between DENV and pre-existing antibodies from previous DENV infection may subvert the innate immune response by downregulating TLR signaling (Modhiran et al., 2010). In a previous study, a differentially expressed TLR 
profile was reported in children with severe dengue, wherein increased expression of TLR7 and TLR4 transcript variant 3 (TLR4R3) and decreased expression of TLR1, TLR2, TLR4R4, and TLR4 cofactor CD14 were observed (de Kruif et al., 2008). As dendritic cells (DCs), monocytes are considered important target cells for DENV infection both in vitro and in vivo (Halstead et al., 1980; Wu et al., 2000). A previous study reported a reduced number of $\mathrm{CD} 14(+)$ human leukocyte antigen (HLA)DR $(+)$ monocytes in patients with severe dengue compared to those with mild dengue and controls (Azeredo et al., 2010). In addition, CD14(+) monocytes expressing TLR2 and TLR4 were increased in peripheral blood from mild dengue patients compared to in that of patients with severe dengue, suggesting the protective role of TLR2 and TLR4 in this setting (Azeredo et al., 2010). Increased TLR3 and TLR9 expression was found in DCs of patients with dengue fever (DF) early in infection, and poor stimulation of TLR3 and TLR9 was observed in DCs from patients with severe manifestations, suggesting a role for TLRs in dengue pathogenesis (Torres et al., 2013). Additionally, lower TLR2 expression was found in patients with DF compared to in those with DHF (Torres et al., 2013). A previous study reported the involvement of TLR3, 7, and 8 in the recognition of the DENV-2 NGC strain, and a strong induction of IL- 8 and IFN- $\alpha / \beta$ responses mainly produced by TLR3 signaling was found to inhibit viral replication in HEK293 and U937 cell lines (Tsai et al., 2009). However, the DENV2 NGC strain induced IL-6 expression in U937 cells, but not in THP-1 cells. This finding is in contrast with a previous study that reported IL-6 expression in THP-1 cells by DENV-2 16681 strain infection (Chareonsirisuthigul et al., 2007); however, this discrepancy could be attributed to the difference between the DENV-2 strains. A previous study showed that TLR3 can inhibit the replication of DENV-2 in HepG2 cells by inducing IFN- $\beta$ expression (Liang et al., 2011). Another study reported that TLR3, 7, and 8 can induce inflammatory and humoral responses in rhesus macaques and suppress DENV-1 Western Pacific 74 strain replication (Sariol et al., 2011). Based on myeloid and plasmacytoid dendritic cells (mDCs and pDCs), DENV replication and cytokine responses may differ. TLR7-mediated recognition of DENV-2 (strain 16803) and increased IFN- $\alpha$ production in pDCs has been previously reported (Sun et al., 2009). Nasirudeen et al. (2011) showed that DENV infection induces intracellular RNA virus sensors, including RIG-I, MDA5, and TLR3, and essential components of host defense. In addition, RIG-I and MDA5 showed an inhibitory role against DENV-1 in $\mathrm{HuH}-7$ cells alongside significantly increased IFN- $\beta$ expression (Nasirudeen et al., 2011). However, despite the knockdown of RIG-I and MDA5, the level of IFN- $\beta$ production was increased upon DENV-1 infection due to TLR3 activation (Nasirudeen et al., 2011). TLR3 can detect double-stranded RNA (dsRNA), a molecular pattern associated with viral infection (Alexopoulou et al., 2001). Moreover, in a recent study, poly(ADP-ribose) polymerase 9 (PARP9), a non-canonical sensor for RNA virus was shown to recognize and bind viral or poly I:C dsRNA activating the phosphoinositide 3-kinase (PI3K) and AKT3 pathway to produce IFN- $\alpha$, independent of mitochondrial antiviral signaling (MAVS) and exerts antiviral effects (Xing et al., 2021a). However, the role of PARP9 in DENV infection remains to be identified. In addition, a recent study demonstrates that RNA helicase DEAHbox helicase 15 (DHX15) exerts its antiviral role independent of RIG-I and MDA5 by inducing the production of IFN- $\beta$, IFN$\lambda 3$, and IL-18 in response to dsRNA poly I:C or enteric RNA virus rotavirus or reovirus infection (Xing et al., 2021b), which highlights the importance of future investigation of the antiviral role of DHX15 in DENV infection. However, another study showed the induction of TLR2 and TLR6 signaling pathways and downstream IL- 6 and TNF- $\alpha$ production by DENV NS1 protein after DENV-2 infection in human peripheral blood mononuclear cells (PBMCs; Chen et al., 2015). Notably, DENV-2-infected and NS1 protein-treated TLR6-/- mice showed higher survivability than DENV-2-infected and NS1 protein-treated wild-type mice, suggesting a role for TLR6 in DENV immunopathogenesis in this model (Chen et al., 2015). Modhiran et al. also reported that NS1 activates TLR4 signaling pathways, leading to the production of proinflammatory cytokines and chemokines (Modhiran et al., 2015, 2017). However, a previous study reported that DENV NS1 does not inhibit TLR3 signaling (Baronti et al., 2010). Sirtuins (SIRTs 1-7) are a family of nicotinamide adenine dinucleotide (NAD)-dependent deacetylases that play an important role in controlling inflammation by regulating immune gene transcription. In a recent study, $\mathrm{Li}$ et al. (2018) demonstrated that SIRT6 negatively regulates the DENVinduced inflammatory response through TLR3 and RLR signaling pathways. NS1-induced platelet activation via TLR4 on platelets has been reported, which may lead to thrombocytopenia and hemorrhage (Chao et al., 2019; Quirino-Teixeira et al., 2020). It has been reported that individuals with a heterozygous genotype for TLR4 Asp299Gly and Thr399Ile polymorphisms showed higher susceptibility to DENV infection (Sharma et al., 2016), suggesting the role of TLR4 in DENV infection. A recent study reported decreased expression of TLR3, 7, and 9 in monocytederived DCs (MDDCs) after oral supplementation with vitamin D (4,000 IU/day) (Martinez-Moreno et al., 2020). In addition, a decrease in IL-12 and IL-8 levels and an increase in IL10 expression were observed, and the cells showed reduced susceptibility to DENV-2 infection (Martinez-Moreno et al., 2020). However, a previous study reported no significant change in TLR expression after oral supplementation with vitamin D (Giraldo et al., 2018), which could be attributed to differences between cell types.

It has been demonstrated that DENV NS1 protein alone may induce vascular leakage and inflammatory cytokine secretion. This could be prevented using NS1-immune polyclonal mouse serum or monoclonal antibodies against NS1, suggesting that DENV NS1 is a key player in DENVinduced immunopathogenesis (Beatty et al., 2015). TLR9 knockdown was reported to inhibit DENV-induced IFN- $\lambda 1$, IFN- $\lambda 2$, IFN- $\lambda 3$, and IFN- $\beta 1$ mRNA expression, suggesting the antiviral role of TLR9 signaling in DENV infection (Lai et al., 2018). A previous in vitro study reported the potential of IFN- $\lambda 1$ to inhibit DENV-2 replication (Palma-Ocampo et al., 2015), the production of which may involve TLR3, IRF-3, and NF- $\mathrm{KB}$ molecules; furthermore, NS1 protein may remain the main viral component that induces IFN $-\lambda 1$ production 
(Hsu et al., 2016). It was recently demonstrated that TLR2, together with its coreceptors CD14 and TLR6, has a potential role in modulating vascular integrity during DENV infection (Aguilar-Briseno et al., 2020). Analysis of TLR expression in DENV-infected corneas revealed upregulation of TLR4, TLR7, TLR9, and TLR10 (Parthasarathy et al., 2018), which may lead to an increased innate proinflammatory response in the cornea. In a recent study of DENV and chikungunya virus (CHIKV) coinfection, the TLR7 and TLR8 polymorphisms have been linked to susceptibility to or protection against infections (Sengupta et al., 2021), suggesting the crucial role of TLRs in DENV infection. In our previous study, we showed that tupaia lung fibroblast cells are susceptible to all four serotypes of DENV infection, and tupaia TLR8 may possess antiviral potential against DENV infection (Kayesh et al., 2017). The pathogenesis of dengue is immune-mediated and complex, and regulatory $\mathrm{T}$ cells (Tregs) may suppress the immune response and contribute to better prognosis. A recent study reported altered profiles of Tregs and associated cytokines in mild and moderate dengue. Mild cases had significantly higher levels of Tregs, and IL-6 and IL-8 levels were found to be negatively correlated with Treg levels (Tillu et al., 2016). However, the molecular pathways involved in Treg proliferation are poorly understood. A double-faced implication of CD $4+$ Foxp3 + Tregs expanded by acute dengue infection via the TLR2/MyD88 pathway has been reported in a murine model (George et al., 2020). DENV infection has been reported to induce CD4 + Foxp3 + Treg proliferation via the TLR2/MyD88 pathway. Furthermore, dengue-infected hosts are more susceptible to sepsis, which could be due to early TLR2-dependent proinflammatory cytokine production (George et al., 2020). CD4 + Foxp3 + Treg cells may dampen induction of the immune response; therefore, these cells should be contained to allow effective protection against pathogens, including viruses. Based on these findings, it is important to investigate the implications of high CD4 + Foxp3 + Treg levels in DENV infections. Aside from RNA sensors, DENV can activate cytosolic DNA-specific sensors and cGAS signaling through the release of mitochondrial DNA (mtDNA) into the cytosol. DENV can also trigger a cGAS-mediated antiviral response, which highlights an indirect activation of DNA-specific innate immune signaling pathway by DENV infection (Sun et al., 2017). Moreover, the contributions of DENV-induced immune activation by TLR9 and cGAS are comparable (Sun et al., 2017; Lai et al., 2018). For simplicity, the above findings obtained in different cells/systems have been indicated in Figure 1 without indication of cell type/system, and highlighting that various TLRs are implicated in DNEV replication (Figure 1), which may impact viral pathogenesis. Therefore, a complete understanding of TLRs in DENV infection is critical for designing a successful therapeutic or preventive intervention.

\section{INHIBITION OF INNATE IMMUNE RESPONSE BY DENV}

An improved understanding of DENV immune evasion is crucial for the rational development of anti-DENV tools. Like many other viruses, DENV employs a variety of mechanisms to avoid, reduce, or disrupt antiviral immunity and establish infection. Mice with impaired type I IFN signaling have enhanced susceptibility to DENV infection, suggesting the role of IFN in inhibiting DENV infection (Zust et al., 2014). Inhibition of type I IFN signaling is a crucial mechanism of DENV immune evasion. TLRs play a role in the antiviral innate immune response, as indicated above, and DENV also possesses mechanisms to antagonize the host antiviral innate immune response to establish infection. Here, we discuss how DENV evades the host innate immune response to establish infection, with a particular focus on the inhibition of TLR signaling (Figure 1) and type I IFN production. It has been shown that DENV cannot infect IFN- $\alpha / \beta$-treated human cells; however, IFN treatment after DENV infection could not inhibit viral replication, suggesting that DENV possesses the tools to inhibit IFN (Diamond et al., 2000). In a previous study, DENV2 proteins NS2A, NS4A, and NS4B were identified as IFN antagonists (Munoz-Jordan et al., 2003). It has been shown that NS4B blocks the IFN-induced signal transduction cascade by interfering with signal transducer and activator of transcription (STAT) 1 activation (Munoz-Jordan et al., 2003). It has been reported that the catalytically active NS2B3 protein complex antagonizes type I IFN response in human DCs (RodriguezMadoz et al., 2010a). Furthermore, DENV infection in primary human DCs reportedly does not induce IRF-3 phosphorylation, which results in the inhibition of type I IFN synthesis (RodriguezMadoz et al., 2010b). However, non-canonical IRF-3, IRF-5, and IRF-7-independent antiviral defense mechanisms in DENV infection have been demonstrated in AG129 mice, which are mediated by IRF-1 through IL-12/IFN- $\gamma$ production (Carlin et al., 2017). A previous study also showed the induction of IRF-1 and IRF-7 in DENV-2 infection in A549 cells (Chang et al., 2006); however, the mechanism of IRF-1 induction remains to be confirmed. In a previous study, Jones et al. (2005) reported that DENV can subvert the human IFN response by downregulating STAT2 expression. Several studies have reported that DENV NS5 is a potent antagonist of type I IFNs. These type I IFNs can degrade STAT2, a necessary component of the type I IFN signaling pathway, and thus help in DENV replication (Mazzon et al., 2009; Ashour et al., 2010; Morrison et al., 2013). DENV NS1 protein levels in serum may induce changes in innate immune parameters, which may contribute to different clinical outcomes of DENV infection. Carvalho et al. (2014) showed that higher NS1 levels in serum may induce a reduced TLR4 response to LPS. Recently, Murphy Schafer et al. (2020) introduced an additional mechanism of TLR signaling disruption by DENV-2. DENV-2 infection induces SIAH1 expression, resulting in SIAH1 binding and ubiquitination of MyD88, an adaptor protein of TLR signaling, thereby dampening the host innate immune response and promoting viral replication.

Although originally stimulator of interferon genes (STING) was described as a response to cytosolic DNA sensing (Zhang et al., 2011), a recent study indicated that STING is also activated upon RNA virus infection (Holm et al., 2016). STING plays an important role in the induction of type I IFN responses 


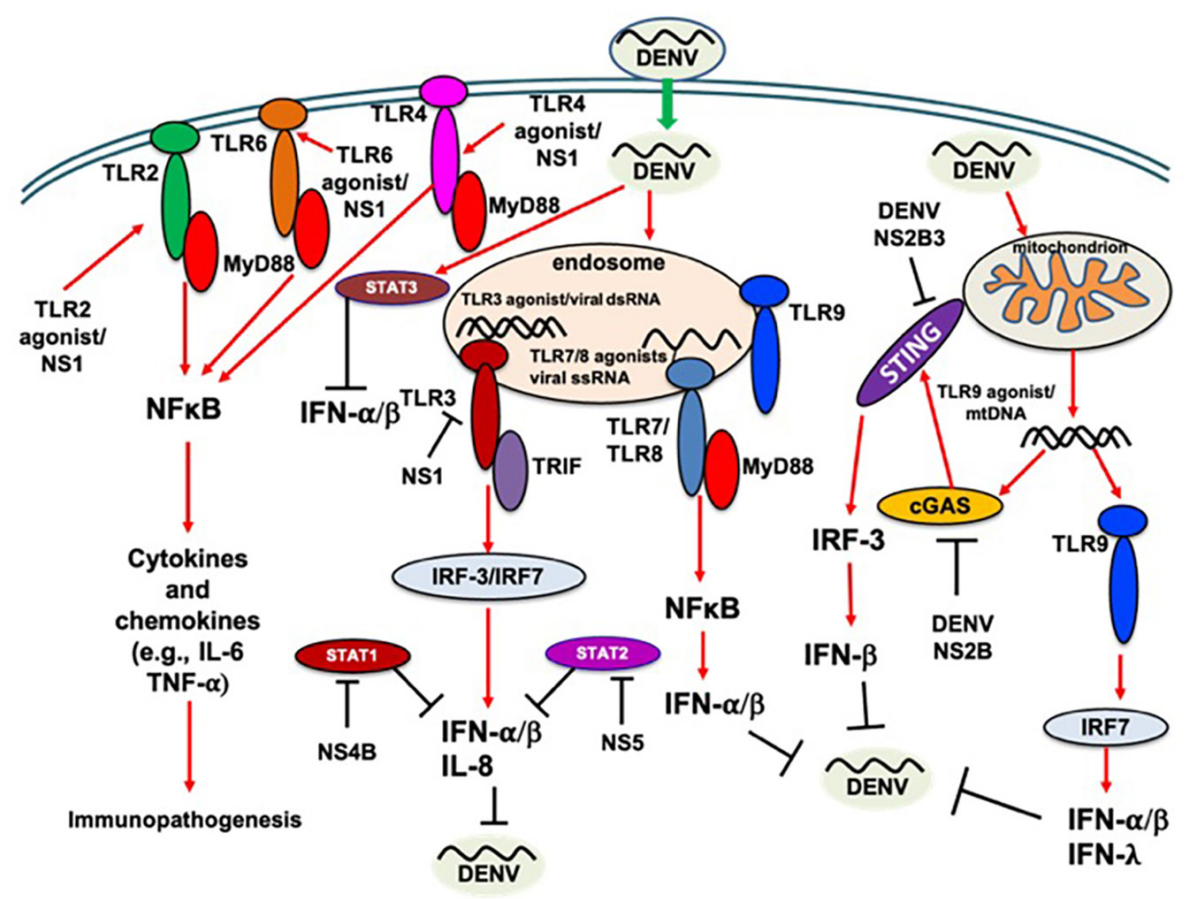

FIGURE 1 | TLR response to DENV infection. Red arrow indicates the induction/activation of components of TLR signaling by DENV; black line indicates the inhibition or cleavage or degradation of the host immune components/response or inhibition of DENV replication, as appropriate.

against viral infections (Ishikawa et al., 2009). DENV can inhibit IFN production by targeting the cGAS/STING signaling pathway, and it has been shown that the DENV NS2B3 protease complex can cleave human STING, but not mouse STING (Aguirre et al., 2012; Yu et al., 2012; Stabell et al., 2018). Stabell et al. (2018) also discovered that DENV cannot inactivate STING in most primates, including chimpanzees (Pan troglodytes), rhesus macaque (Macaca mulatta), and common marmosets (Callithrix jacchus). A recent study showed that DENV NS2B can target cGAS for degradation, thus preventing mtDNA sensing through cGAS during DENV infection (Aguirre et al., 2017). Another study showed that DENV infection inhibits STINGmediated innate immunity in a haplotype-specific manner ( $\mathrm{Su}$ et al., 2020). Moreover, in a murine model, it has been shown that DNEV-induced illness may result from dysregulated STING-mediated vasculopathy (Warner et al., 2017). In a recent study, Ye et al. (2021) showed that USP18 induced by DENV-2 infection is a critical host factor used by DENV-2 to antagonize IFN- $\alpha$ production. Ye et al. (2021) demonstrated that DENV-2 infection increased USP18 expression; USP18 overexpression enhanced DENV-2 replication, while USP18 silencing inhibited DENV-2 replication by activating the IFN$\alpha$-mediated JAK/STAT signaling pathway. A recent study reported a dose-dependent inhibition of DENV replication with (E)-guggulsterone, which stimulates nuclear factor erythroid 2-related factor 2 (Nrf2)-mediated heme oxygenase-1 (HO-1) expression; this expression increased the antiviral IFN response and downstream antiviral gene expression by blocking DENV $\mathrm{NS} 2 \mathrm{~B} / 3 \mathrm{~B}$ protease activity (Chen et al., 2021). However, in an in vitro study, Ferrari et al. (2020) showed that the DENV NS2B3 protease complex can target and promote Nrf2 degradation. A recent study revealed that DENV could utilize STAT3 as a proviral factor for its propagation in A549 cells. In these cells, DENV strategically tweaks the negative regulator of type I IFN signaling, STAT3, to evade host type I and type III IFN responses by upregulating STAT3 expression and activation (Srivastava et al., 2021).

\section{DENV VACCINES UNDER DEVELOPMENT}

The lack of an effective vaccine that can simultaneously protect against the four DENV serotypes in naive individuals remains an unsolved issue. Moreover, the use of the CYD-TDV vaccine as a primary prevention strategy for DENV infection is compromised. However, the limited efficacy and safety issues of the CYD-TDV vaccine have led to the development of safer and more effective vaccine candidates for dengue prevention and control. Five types of dengue vaccines are currently under development: a live-attenuated vaccine, an inactivated virus vaccine, a subunit vaccine, a viral vectored vaccine, and a DNA vaccine (Deng et al., 2020; Huang et al., 2021). For details of the dengue vaccine candidates and their development, please refer to the study by Pinheiro-Michelsen et al. (2020). Several vaccine candidates, including TAK-003, TV003/TV005, TDENF17/F19, TDEN PIV, V180, and TVDV, are present in the clinical pipeline (Idris et al., 2021). Here, we will briefly 
discuss the first dengue vaccine, CYD-TDV, and other dengue vaccine candidates, including TAK-003 and TV003/TV005, in their late-stage development. The advances in these vaccines are summarized in Table 1.

\section{CYD-TDV}

The first licensed dengue vaccine, CYD-TDV, is a chimeric dengue-yellow fever virus 17D (YF17D) vaccine that was constructed by replacing the prM/E RNA sequences of YF17D with corresponding sequences of the DENV-1-4 serotypes (Guy et al., 2010). Data from phase III trials revealed that vaccine efficacy varies depending on age, serotype, and serostatus, and a low vaccine efficacy for DENV-1 (50.3\%) and DENV2 (42.3\%) has been reported (Villar et al., 2015). Moreover, a higher risk of hospitalization has been observed in children younger than 9 years of age (Sridhar et al., 2018). Threat of $\mathrm{ADE}$ has also been reported in seronegative individuals who were sensitized by the vaccine (Halstead, 2017). Despite some limitations of the CYD-TDV vaccine, this vaccine should contribute to the control of DENV infection in seropositive individuals in dengue-endemic areas/countries. In a phase III clinical trial in Columbia, it has been observed that the efficacy of CYD-TDV against symptomatic virologically confirmed dengue (VCD) was 67.5\%; CYD-TDV was found to be a useful tool to consider as part of an integrated control strategy against endemic dengue (Reynales et al., 2020). In compliance with recommendations by the WHO, a recent study highlighted the importance of prevaccination screening for detecting previous dengue infection during vaccination with CYD-TDV; this is crucial to provide protection against dengue disease and reduce the risk of dengue hospitalization and severe dengue (DiazGranados et al., 2021). Therefore, it is important to develop cost-effective and reliable diagnostic tools for rapid prevaccination screening (Wilder-Smith et al., 2019), which may enhance the use of CYD-TDV and assist with dengue control in dengue-endemic areas. In a randomized, controlled, phase II, non-inferiority study of CYD-TDV in healthy individuals aged 9-50 years, the one- and two-dose groups were compared to the three-dose group. The twodose CYD-TDV regimen was revealed as an alternative to the licensed three-dose regimen in seropositive subjects at baseline and aged 9 years and older (Coronel-Martinez et al., 2021). Moreover, in low-resource settings, vaccination with a reduced number of doses may lead to improved vaccine compliance and coverage.

\section{TAK-003}

TAK-003 (previously called DENVax), Takeda's tetravalent dengue vaccine candidate, is based on a live-attenuated DENV2 (DEN2-PDK-53). The latter vaccine provides the genetic backbone into which three chimeric viruses containing the prM and E proteins of DENV-1, DENV-3, and DENV-4 are inserted (Osorio et al., 2016). Therefore, there is a difference between the vaccine components of Dengvaxia and TAK-003, as the DENV-2 backbone contains the non-structural proteins. In phase I and II clinical trials, TAK-003 was found to be immunogenic and well tolerated; high titers of nAbs were detected against

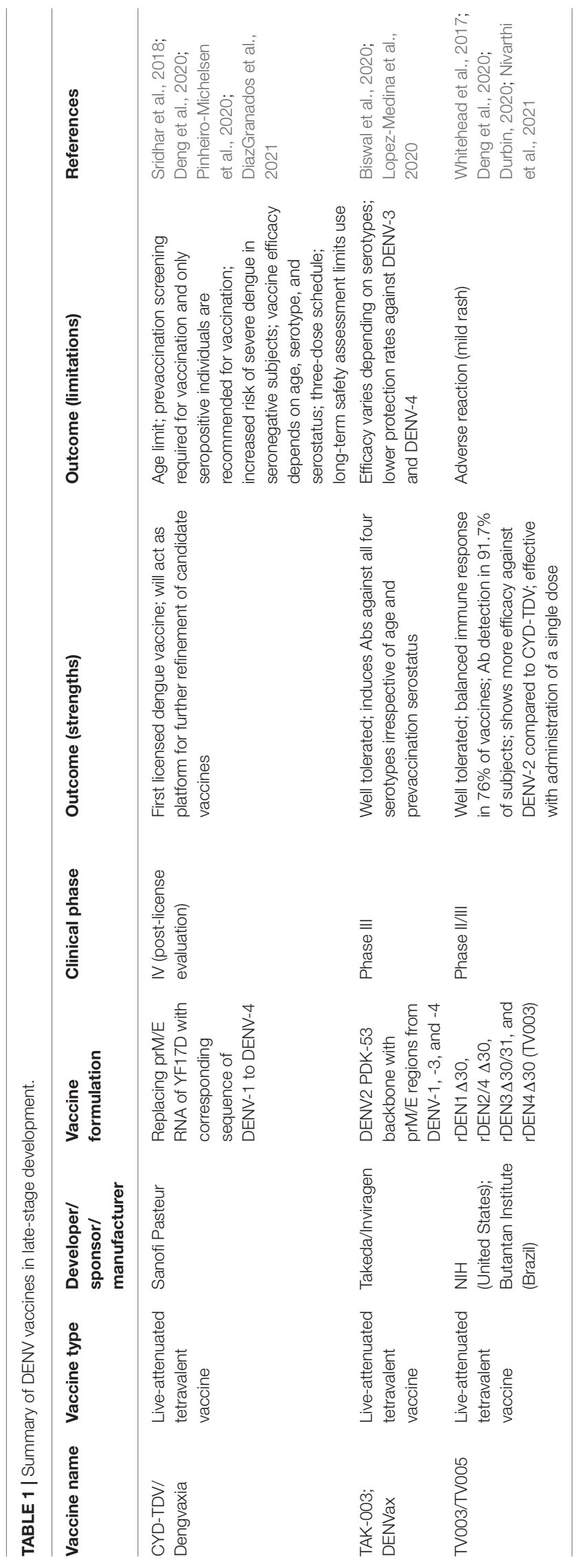


all four serotypes, irrespective of age and prevaccination dengue exposure (Osorio et al., 2014; George et al., 2015; Rupp et al., 2015; Sirivichayakul et al., 2016; Saez-Llorens et al., 2018; Tricou et al., 2020a,b). A phase II, double-blind, placebocontrolled trial of TAK-003 in children aged 2-17 years living in dengue-endemic countries showed antibody responses against all four serotypes, which persisted for 4 years post-vaccination (Tricou et al., 2020b). A phase II clinical trial with one or two doses of a lyophilized TAK-003 revealed seropositivity after only one dose against the DENV-2 serotype; however, seropositivity to all four serotypes was achieved after two doses (Turner et al., 2020). In a multicenter phase III clinical trial, TAK003 showed an overall vaccine efficacy of $73.3 \%$, regardless of the serostatus before vaccination; this efficiency was measured after 17 months of vaccination with two doses administered three months apart (Biswal et al., 2020). However, similar to Dengvaxia, the efficacy of TAK-003 varies depending on the serotype, and lower protection rates have been shown against DENV-3 (48.9\%) and DENV-4 (51.0\%) (Biswal et al., 2020; Lopez-Medina et al., 2020). TAK-003 immunization reportedly elicits potent cellular immunity against structural and non-structural proteins of all four DENV serotypes; this immunity is maintained for at least 4 months post-vaccination, with focused reactivity against NS1 and NS3 (Waickman et al., 2019). Notably, a previous study reported live-attenuated tetravalent dengue vaccine (TDV)induced CD8 + T cells targeting NS1, NS3, and NS5 proteins of attenuated DENV-2 (Chu et al., 2015); however, vaccine-induced $\mathrm{CD} 8+\mathrm{T}$ cell responses were not reported in the subsequent clinical trials of this candidate vaccine.

\section{TetraVax-DV- TV003/TV003/TV005/Butantan DV}

The live-attenuated tetravalent DENV vaccine candidate TV003/TV005 was developed by the Laboratory of Infectious Diseases at the National Institutes of Health. The vaccine was also licensed by several manufacturers for development, including the Butantan Institute, Brazil, which initiated a Phase III clinical trial (Durbin, 2020). TV003/TV005 consists of rDEN1 $\Delta 30$, $\operatorname{rDEN} 4 \Delta 30, \operatorname{rDEN} 3 \Delta 30 / 31$, and $\operatorname{rDEN} 2 / 4 \Delta 30 . \operatorname{rDEN} 1 \Delta 30$ and $\mathrm{rDEN} 4 \Delta 30$ contain deletions in the $3^{\prime}$ untranslated region (UTR) of DENV-1 and DENV-4, rDEN3 $\Delta 30 / 31$ contains an extra deletion in the $3^{\prime}$ UTR of DENV-3, and $\operatorname{rDEN} 2 / 4 \Delta 30$ is a chimeric virus in which the prM/E sequence of DENV-2 replaced those of the DEN4 $\Delta 30$ vaccine candidate (Kirkpatrick et al., 2015). However, there is a slight difference between TV003 and TV005 with respect to the dose of the $\mathrm{rDEN} 2 / 4 \Delta 30$ component; TV003 contains $10^{3} \mathrm{PFU}$ rDEN2/4 $\Delta 30$, while TV005 contains $10^{4} \mathrm{PFU}$ (Durbin, 2020). In a phase I trial, TV003/TV005 was found to be immunogenic and well tolerated, and administration of a single dose induced seroconversion to all four DENV serotypes in 74-92\% (TV003) and 90\% (TV005) of flavivirus-naive adults (Kirkpatrick et al., 2015; Whitehead, 2016). Notably, both the first and second doses (6 months apart) were well tolerated; however, no significant increase in antibody titers was observed upon administration of the booster dose (Kirkpatrick et al., 2015), suggesting that a single dose of the vaccine is likely to prevent viral infection. It has also been reported that a single dose induces robust tetravalent antibody and cellular T cell responses and is comparable to natural dengue infection (Weiskopf et al., 2015). A previous study reported that TV005 vaccination elicits CD4 + cell responses that are closely mirrored, as observed in a population associated with natural immunity (Angelo et al., 2017). TV003 was also found to be well tolerated in flavivirus-experienced individuals and induced robust $\mathrm{nAb}$ titers (Whitehead et al., 2017). In a phase I clinical study in 21 dengue-naive individuals with a single dose of TV003, 76\% of the subjects developed serotype-specific nAbs. Following challenge with a partially attenuated DENV-2 strain, all 21 subjects were protected, indicating the induction of immunity by each of the vaccine components (Nivarthi et al., 2021). In another study, TV003 was found to be well tolerated, except for a mild rash as an adverse reaction; a single dose induced seroconversion against all four DENV serotypes in $91.7 \%$ of subjects, with $100 \%$ seroconversion against DENV-2, DENV-3, and DENV-4 (Kirkpatrick et al., 2016). It was observed that a single dose of TV003 or TV005 in flavivirus-naïve subjects induced a cumulative serologic response in 89.8 and $92.1 \%$ of cases, respectively (Durbin, 2020), suggesting that TV005 showed slightly better efficacy than TV003. Overall, TV003/TV005 showed improved efficacy compared with CYDTDV. In a phase II, randomized, multicenter, double-blind, and controlled clinical trial in adults aged $18-59$ years, Butantan-DV and TV003 were evaluated. Both Butantan-DV and TV003 were immunogenic and well tolerated; they induced robust, balanced $\mathrm{nAb}$ responses against the four DENV serotypes without any serious adverse reactions. However, rash was observed as the most frequent adverse reaction in the groups vaccinated with either Butantan-DV or TV003 (Kallas et al., 2020).

\section{CHALLENGES TO OVERCOME IN DENV VACCINE DEVELOPMENT}

To date, there is no vaccine that provides cross-protection against all human DENV serotypes (Scherwitzl et al., 2017). The development of a universal dengue vaccine that is equally protective against all serotypes is a long-sought goal in dengue research. However, it has become challenging to develop a universal DENV vaccine owing to some limitations. One of the major limitations in DENV vaccine development is the existence of multiple DENV subtypes and different virulence mechanisms in different strains (Idris et al., 2021). ADE of disease appears to be a public health concern regarding the development of vaccines and antibody therapies; the mechanisms underlying antibody protection against viruses might have the potential to enhance infection or induce immunopathology (Arvin et al., 2020). DENV vaccine development is also threatened by ADE in heterotypic DENV infection in the presence of subprotective/non-neutralizing antibodies that may cause severe dengue (Katzelnick et al., 2017). Previous DENV vaccine studies revealed human clinical safety risks related to ADE (Dejnirattisai et al., 2010; Halstead, 2017; Sridhar et al., 2018). 
A recent study indicated that the TLR2/MyD88-mediated Th2biased immune response to primary DENV infection could favor secondary DENV infection to DHF/DSS via ADE (George et al., 2017). Therefore, balanced and durable immunity to all four DENV serotypes is of great importance for dengue vaccine development and avoiding the danger of $\mathrm{ADE}$ in subsequent infections. The lack of a suitable validated immunocompetent small animal model for vaccine testing and of defined immune correlates of protective immunity also represent a significant obstacle to vaccine development efforts (Idris et al., 2021). Therefore, it is important to investigate an alternative suitable immunocompetent animal model that could be used for testing vaccine efficacy (Jiang et al., 2021). Travel-associated DENV infection is a threat in dengue-endemic countries (Halstead and Wilder-Smith, 2019), and controlling travel-associated dengue vaccines for travelers is essential. Therefore, the dosages of vaccines also need to be considered during their development; for example, Dengvaxia requires three doses six months apart, which may limit its use in travelers. However, the TAK003 and TV003/TV005, which are currently under phase III clinical trials and yet to obtain licenses, are currently being considered for two doses three months apart and a single dose, respectively. Moreover, the limited number of studies also hinders the identification of the underlying mechanism(s) of vaccine efficacy for developing a universal dengue virus. Clinical trials with a leading candidate vaccine demonstrated that unbalanced replication and immunodominance of one vaccine component over others may result in low efficacy and vaccine-induced severe disease (Nivarthi et al., 2021). Selection of attenuated DENV vaccine candidates based on plaque size led to mixed safety outcomes in clinical trials, which compromise the use of plaque size as an indicator of DENV attenuation (Bifani et al., 2021). Therefore, a reliable marker of DENV attenuation is important for vaccine candidates. Notably, a recent study indicated that genome diversity of DENV could be developed as a marker of DENV attenuation (Bifani et al., 2021). Another obstacle in dengue vaccine development is that virus-neutralizing antibodies do not invariably correlate with vaccine efficacy; therefore, other markers that may predict protection, including cell-mediated immunity, are urgently needed. A recent study showed the induction of DENVspecific CD4 $+\mathrm{T}$ cell responses after vaccination with a monovalent purified inactivated virus (PIV) vaccine candidate against DENV-1 adjuvanted with alum (Friberg et al., 2020). A better understanding of antibody responses that correlate with protection against DENV infection by all four serotypes is of great importance for developing a uniformly effective vaccine (Martinez et al., 2021). Recently, mRNA vaccines have shown the potential to be used against SARS-CoV-2 infection and successfully combatting the pandemic, although long-term safety has yet to be confirmed (Cai et al., 2021). A previous study also showed the potential of an mRNA vaccine encoding DENV1-NS-induced immunogenicity and protection in transgenic mice (Roth et al., 2019). Therefore, mRNA vaccines may open a new window for an effective DENV vaccine. Based on this information, it is important to enhance vaccine efficacy by improving the design of safe, effective, and affordable vaccines against dengue, including the use of various adjuvants such as TLR agonist adjuvants (Van Hoeven et al., 2018; Bidet et al., 2019).

The concept of trained immunity or innate immune memory is not only present in plants or invertebrates, but also in mammals (Quintin et al., 2014; Netea et al., 2016). TLRs are considered as the important triggerering molecule of trained immunity (Sanchez-Ramon et al., 2018), and have been dicussed in several recently published reviews (Netea et al., 2020; Owen et al., 2020;Pulendran et al., 2021). TLR agonists as vaccine adjuvants are currently under investigation for different human vaccines and appear as promising in the vaccine study (Bendelac and Medzhitov, 2002; Duthie et al., 2011; Pulendran et al., 2021). TLR agonist(s) may activate specific TLR(s) and enhance vaccine efficacy without direct participation in the protective immunity (Kumar et al., 2019). TLRs have been shown to activate Th1 response, and control and shape adaptive immune responses (Schnare et al., 2001). Effective TLR agonists enhance the targeted cellular or humoral adaptive responses that have been observed in several vaccines (Giannini et al., 2006; Del Giudice et al., 2018; Moser et al., 2020). There are several well-known TLR agonists, including triacylated lipopeptides [e.g., Pam3CysSerLys4 (Pam3CSK4) and their derivatives for TLR1/2, poly I:C (synthetic dsRNA) for TLR3, bacterial lipopolysaccharide or Monophosphoryl lipid A for TLR4, bacterial flagellin for TLR5, imiquimod and resiquimod (nucleoside analog) for TLR7/8, and CpG ODN for TLR9, which could be investigated for the utilization as dengue vaccine adjuvants (Duthie et al., 2011; Bidet et al., 2019)]. Although the understanding of TLR response to DENV infection made in this study should be an aid in the selection of TLR agonists to be used in dengue vaccine, however, an extensive research requires to find out the potential TLR agonist candidate for dengue vaccine. In addition, although vaccine containing TLR agonist should boost vaccine efficacy, the safety issues related to enhanced TLR signaling pathways due to TLR agonists require to be critically evaluated, which constitute an area of active investigation.

\section{CONCLUSION}

The development of a safe and efficacious vaccine that can be used against all DENV serotypes, regardless of serostatus, remains a large challenge; however, its development may benefit from a better understanding of host innate immune responses, particularly interaction between TLRs and viral components. Several studies have shown the potential of TLR agonists as vaccine adjuvants, which could be investigated in the case of candidate DENV vaccines to enhance their protective efficacy. Furthermore, bridging and post-licensure studies are required to extend the conclusions concerning vaccine characteristics, and coadministration trials are necessary in pediatrics (Hombach, 2009). It is difficult to achieve effective, long-lasting, and uniform protection against all four DENV serotypes with the existing vaccine; it is also challenging to develop a safe and effective pan-serotype dengue vaccine. Therefore, the development of therapeutic agents against DENV and vector control programs 
should be enhanced. Until an effective vaccine is available, the mainstays of dengue prevention, such as disease surveillance and vector population control, should be properly implemented.

\section{AUTHOR CONTRIBUTIONS}

MEHK, MK, and KT-K: conceptualization and writing - review and editing. MEHK: writing - original draft preparation. KT-K:

\section{REFERENCES}

Aguas, R., Dorigatti, I., Coudeville, L., Luxemburger, C., and Ferguson, N. M. (2019). Cross-serotype interactions and disease outcome prediction of dengue infections in Vietnam. Sci. Rep. 9:9395.

Aguilar-Briseno, J. A., Upasani, V., Ellen, B. M. T., Moser, J., Pauzuolis, M., RuizSilva, M., et al. (2020). TLR2 on blood monocytes senses dengue virus infection and its expression correlates with disease pathogenesis. Nat. Commun. 11:3177.

Aguirre, S., Luthra, P., Sanchez-Aparicio, M. T., Maestre, A. M., Patel, J., Lamothe, F., et al. (2017). Dengue virus NS2B protein targets cGAS for degradation and prevents mitochondrial DNA sensing during infection. Nat. Microbiol. 2:17037.

Aguirre, S., Maestre, A. M., Pagni, S., Patel, J. R., Savage, T., Gutman, D., et al. (2012). DENV inhibits type I IFN production in infected cells by cleaving human STING. PLoS Pathog. 8:e1002934. doi: 10.1089/jir.2014.0129

Alexopoulou, L., Holt, A. C., Medzhitov, R., and Flavell, R. A. (2001). Recognition of double-stranded RNA and activation of NF-kappaB by Toll-like receptor 3 . Nature 413, 732-738. doi: 10.1038/35099560

Angelo, M. A., Grifoni, A., O'rourke, P. H., Sidney, J., Paul, S., Peters, B., et al. (2017). Human CD4(+) T cell responses to an attenuated tetravalent dengue vaccine parallel those induced by natural infection in Magnitude, HLA restriction, and antigen specificity. J. Virol. 91:e02147-1. doi: 10.1128/JVI. 02147-1

Arvin, A. M., Fink, K., Schmid, M. A., Cathcart, A., Spreafico, R., HavenarDaughton, C., et al. (2020). A perspective on potential antibody-dependent enhancement of SARS-CoV-2. Nature 584, 353-363.

Ashour, J., Morrison, J., Laurent-Rolle, M., Belicha-Villanueva, A., Plumlee, C. R., Bernal-Rubio, D., et al. (2010). Mouse STAT2 restricts early dengue virus replication. Cell Host Microbe 8, 410-421. doi: 10.1016/j.chom.2010.10.007

Azeredo, E. L., Neves-Souza, P. C., Alvarenga, A. R., Reis, S. R., TorrentesCarvalho, A., Zagne, S. M., et al. (2010). Differential regulation of toll-like receptor-2, toll-like receptor-4, CD16 and human leucocyte antigen-DR on peripheral blood monocytes during mild and severe dengue fever. Immunology 130, 202-216. doi: 10.1111/j.1365-2567.2009.03224.x

Baronti, C., Sire, J., De Lamballerie, X., and Querat, G. (2010). Nonstructural NS1 proteins of several mosquito-borne Flavivirus do not inhibit TLR3 signaling. Virology 404, 319-330. doi: 10.1016/j.virol.2010.05.020

Beatty, P. R., Puerta-Guardo, H., Killingbeck, S. S., Glasner, D. R., Hopkins, K., and Harris, E. (2015). Dengue virus NS1 triggers endothelial permeability and vascular leak that is prevented by NS1 vaccination. Sci. Transl. Med. 7:304ra141. doi: $10.1126 /$ scitranslmed.aaa3787

Bendelac, A., and Medzhitov, R. (2002). Adjuvants of immunity: harnessing innate immunity to promote adaptive immunity. J. Exp. Med. 195, F19-F23.

Bhatt, S., Gething, P. W., Brady, O. J., Messina, J. P., Farlow, A. W., Moyes, C. L., et al. (2013). The global distribution and burden of dengue. Nature 496, 504-507.

Bidet, K., Ho, V., Chu, C. W., Naim, A. N. H., Thazin, K., Chan, K. R., et al. (2019). Mimicking immune signatures of flavivirus infection with targeted adjuvants improves dengue subunit vaccine immunogenicity. NPJ Vaccines 4:27.

Bifani, A. M., Choy, M. M., Tan, H. C., and Ooi, E. E. (2021). Attenuated dengue viruses are genetically more diverse than their respective wild-type parents. NPJ Vaccines 6:76.

Biswal, S., Borja-Tabora, C., Martinez Vargas, L., Velasquez, H., Theresa Alera, M., Sierra, V., et al. (2020). Efficacy of a tetravalent dengue vaccine in healthy children aged 4-16 years: a randomised, placebo-controlled, phase 3 trial. Lancet $395,1423-1433$. supervision. All authors have read and agreed to the published version of the manuscript.

\section{FUNDING}

This study was supported by a grant (innovative drug development network) from the Japan Agency for Medical Research and Development (AMED).

Cai, X., Li, J. J., Liu, T., Brian, O., and Li, J. (2021*). Infectious disease mRNA vaccines and a review on epitope prediction for vaccine design. Brief. Funct. Genomics elab027.

Carlin, A. F., Plummer, E. M., Vizcarra, E. A., Sheets, N., Joo, Y., Tang, W., et al. (2017). An IRF- 3-, IRF- 5-, and IRF-7-Independent pathway of dengue viral resistance utilizes IRF-1 to Stimulate Type I and II interferon responses. Cell Rep. 21, 1600-1612. doi: 10.1016/j.celrep.2017.10.054

Carvalho, D. M., Garcia, F. G., Terra, A. P., Lopes Tosta, A. C., Silva Lde, A., Castellano, L. R., et al. (2014). Elevated dengue virus nonstructural protein 1 serum levels and altered toll-like receptor 4 expression, nitric oxide, and tumor necrosis factor alpha production in dengue hemorrhagic Fever patients. J. Trop. Med. 2014:901276.

Chang, T. H., Liao, C. L., and Lin, Y. L. (2006). Flavivirus induces interferonbeta gene expression through a pathway involving RIG-I-dependent IRF-3 and PI3K-dependent NF-kappaB activation. Microbes Infect. 8, 157-171. doi: 10.1016/j.micinf.2005.06.014

Chao, C. H., Wu, W. C., Lai, Y. C., Tsai, P. J., Perng, G. C., Lin, Y. S., et al. (2019). Dengue virus nonstructural protein 1 activates platelets via Toll-like receptor 4, leading to thrombocytopenia and hemorrhage. PLoS Pathog. 15:e1007625. doi: 10.1371/journal.ppat.1007625

Chareonsirisuthigul, T., Kalayanarooj, S., and Ubol, S. (2007). Dengue virus (DENV) antibody-dependent enhancement of infection upregulates the production of anti-inflammatory cytokines, but suppresses anti-DENV free radical and pro-inflammatory cytokine production, in THP-1 cells. J. Gen. Virol. 88, 365-375. doi: 10.1099/vir.0.82537-0

Chen, J., Ng, M. M., and Chu, J. J. (2015). Activation of TLR2 and TLR6 by Dengue NS1 protein and its implications in the immunopathogenesis of dengue virus infection. PLoS Pathog. 11:e1005053. doi: 10.1371/journal.ppat.1005053

Chen, W. C., Wei, C. K., Hossen, M., Hsu, Y. C., and Lee, J. C. (2021). (E)Guggulsterone inhibits dengue virus replication by upregulating antiviral interferon responses through the induction of heme oxygenase-1 expression. Viruses 13:712. doi: 10.3390/v13040712

Chu, H., George, S. L., Stinchcomb, D. T., Osorio, J. E., and Partidos, C. D. (2015). CD8+ T-cell responses in flavivirus-naive individuals following immunization with a live-attenuated tetravalent dengue vaccine Candidate. J. Infect. Dis. 212, 1618-1628. doi: 10.1093/infdis/jiv258

Coronel-Martinez, D. L., Park, J., Lopez-Medina, E., Capeding, M. R., Cadena Bonfanti, A. A., Montalban, M. C., et al. (2021). Immunogenicity and safety of simplified vaccination schedules for the CYD-TDV dengue vaccine in healthy individuals aged 9-50 years (CYD65): a randomised, controlled, phase 2, noninferiority study. Lancet Infect. Dis. 21, 517-528.

Costa, V. V., Fagundes, C. T., Souza, D. G., and Teixeira, M. M. (2013). Inflammatory and innate immune responses in dengue infection: protection versus disease induction. Am. J. Pathol. 182, 1950-1961. doi: 10.1016/j.ajpath. 2013.02.027

de Kruif, M. D., Setiati, T. E., Mairuhu, A. T., Koraka, P., Aberson, H. A., Spek, C. A., et al. (2008). Differential gene expression changes in children with severe dengue virus infections. PLoS Negl. Trop. Dis. 2:e215. doi: 10.1371/journal.pntd. 0000215

Dejnirattisai, W., Jumnainsong, A., Onsirisakul, N., Fitton, P., Vasanawathana, S., Limpitikul, W., et al. (2010). Cross-reacting antibodies enhance dengue virus infection in humans. Science 328, 745-748. doi: 10.1126/science.1185181

Del Giudice, G., Rappuoli, R., and Didierlaurent, A. M. (2018). Correlates of adjuvanticity: a review on adjuvants in licensed vaccines. Semin. Immunol. 39, 14-21. doi: 10.1016/j.smim.2018.05.001 
Deng, S. Q., Yang, X., Wei, Y., Chen, J. T., Wang, X. J., and Peng, H. J. (2020). A review on dengue vaccine development. Vaccines 8:63.

Diamond, M. S., Roberts, T. G., Edgil, D., Lu, B., Ernst, J., and Harris, E. (2000). Modulation of Dengue virus infection in human cells by alpha, beta, and gamma interferons. J. Virol. 74, 4957-4966. doi: 10.1128/.74.11.4957-4966.2000

DiazGranados, C. A., Bonaparte, M., Wang, H., Zhu, M., Lustig, Y., Schwartz, E., et al. (2021). Accuracy and efficacy of pre-dengue vaccination screening for previous dengue infection with five commercially available immunoassays: a retrospective analysis of phase 3 efficacy trials. Lancet Infect. Dis. 21, 529-536. doi: 10.1016/s1473-3099(20)30695-2

Durbin, A. P. (2020). Historical discourse on the development of the live attenuated tetravalent dengue vaccine candidate TV003/TV005. Curr. Opin. Virol. 43, 79-87. doi: 10.1016/j.coviro.2020.09.005

Duthie, M. S., Windish, H. P., Fox, C. B., and Reed, S. G. (2011). Use of defined TLR ligands as adjuvants within human vaccines. Immunol. Rev. 239, 178-196. doi: $10.1111 / j .1600-065 x .2010 .00978 . x$

Ferrari, M., Zevini, A., Palermo, E., Muscolini, M., Alexandridi, M., Etna, M. P., et al. (2020). Dengue virus targets Nrf2 for NS2B3-Mediated degradation leading to enhanced oxidative stress and viral replication. J. Virol. 94:e01551-20. doi: 10.1128/JVI.01551-20

Friberg, H., Martinez, L. J., Lin, L., Blaylock, J. M., De La Barrera, R. A., Rothman, A. L., et al. (2020). Cell-Mediated immunity generated in response to a purified inactivated vaccine for dengue virus type 1. mSphere 5:e00671-19. doi: 10.1128/ mSphere.00671-19

George, J. A., Kim, S. B., Choi, J. Y., Patil, A. M., Hossain, F. M. A., Uyangaa, E., et al. (2017). TLR2/MyD88 pathway-dependent regulation of dendritic cells by dengue virus promotes antibody-dependent enhancement via Th2-biased immunity. Oncotarget 8, 106050-106070. doi: 10.18632/oncotarget.22525

George, J. A., Park, S. O., Choi, J. Y., Uyangaa, E., and Eo, S. K. (2020). Doublefaced implication of CD4(+) Foxp3(+) regulatory T cells expanded by acute dengue infection via TLR2/MyD88 pathway. Eur. J. Immunol. 50, 1000-1018. doi: 10.1002/eji.201948420

George, S. L., Wong, M. A., Dube, T. J., Boroughs, K. L., Stovall, J. L., Luy, B. E., et al. (2015). Safety and immunogenicity of a live attenuated tetravalent dengue vaccine candidate in flavivirus-naive adults: a randomized, double-blinded Phase 1 Clinical Trial. J. Infect. Dis. 212, 1032-1041. doi: 10.1093/infdis/jiv179

Giannini, S. L., Hanon, E., Moris, P., Van Mechelen, M., Morel, S., Dessy, F., et al. (2006). Enhanced humoral and memory B cellular immunity using HPV16/18 L1 VLP vaccine formulated with the MPL/aluminium salt combination (AS04) compared to aluminium salt only. Vaccine 24, 5937-5949. doi: 10.1016/j. vaccine.2006.06.005

Gibbons, R. V., Kalanarooj, S., Jarman, R. G., Nisalak, A., Vaughn, D. W., Endy, T. P., et al. (2007). Analysis of repeat hospital admissions for dengue to estimate the frequency of third or fourth dengue infections resulting in admissions and dengue hemorrhagic fever, and serotype sequences. Am. J. Trop. Med. Hyg. 77, 910-913. doi: 10.4269/ajtmh.2007.77.910

Giraldo, D. M., Cardona, A., and Urcuqui-Inchima, S. (2018). High-dose of vitamin D supplement is associated with reduced susceptibility of monocytederived macrophages to dengue virus infection and pro-inflammatory cytokine production: an exploratory study. Clin. Chim. Acta 478, 140-151. doi: 10.1016/ j.cca.2017.12.044

Guy, B., Guirakhoo, F., Barban, V., Higgs, S., Monath, T. P., and Lang, J. (2010). Preclinical and clinical development of YFV 17D-based chimeric vaccines against dengue. West Nile and Japanese encephalitis viruses. Vaccine 28, 632649. doi: 10.1016/j.vaccine.2009.09.098

Guzman, M. G., Halstead, S. B., Artsob, H., Buchy, P., Farrar, J., Gubler, D. J., et al. (2010). Dengue: a continuing global threat. Nat. Rev. Microbiol. 8, S7-S16.

Hadinegoro, S. R., Arredondo-Garcia, J. L., Capeding, M. R., Deseda, C., Chotpitayasunondh, T., Dietze, R., et al. (2015). Efficacy and long-term safety of a dengue vaccine in regions of endemic disease. N. Engl. J. Med. 373, 1195-1206.

Halstead, S., and Wilder-Smith, A. (2019). Severe dengue in travellers: pathogenesis, risk and clinical management. J. Travel. Med. 26:taz062.

Halstead, S. B. (2017). Dengvaxia sensitizes seronegatives to vaccine enhanced disease regardless of age. Vaccine 35, 6355-6358. doi: 10.1016/j.vaccine.2017. 09.089

Halstead, S. B., Porterfield, J. S., and O'rourke, E. J. (1980). Enhancement of dengue virus infection in monocytes by flavivirus antisera. Am. J. Trop. Med. Hyg. 29, 638-642. doi: 10.4269/ajtmh.1980.29.638
Harris, E., Videa, E., Perez, L., Sandoval, E., Tellez, Y., Perez, M. L., et al. (2000). Clinical, epidemiologic, and virologic features of dengue in the 1998 epidemic in Nicaragua. Am. J. Trop. Med. Hyg. 63, 5-11. doi: 10.4269/ajtmh.2000.63.5

Holm, C. K., Rahbek, S. H., Gad, H. H., Bak, R. O., Jakobsen, M. R., Jiang, Z., et al. (2016). Influenza A virus targets a cGAS-independent STING pathway that controls enveloped RNA viruses. Nat Commun 7:10680.

Hombach, J. (2009). Guidelines for clinical trials of dengue vaccine in endemic areas. J. Clin. Virol. 46(Suppl. 2), S7-S9.

Hsu, Y. L., Wang, M. Y., Ho, L. J., and Lai, J. H. (2016). Dengue virus infection induces interferon-lambdal to facilitate cell migration. Sci. Rep. 6:24 530.

Huang, B., Zhao, J., Unkeless, J. C., Feng, Z. H., and Xiong, H. (2008). TLR signaling by tumor and immune cells: a double-edged sword. Oncogene 27, 218-224. doi: $10.1038 /$ sj.onc. 1210904

Huang, C. H., Tsai, Y. T., Wang, S. F., Wang, W. H., and Chen, Y. H. (2021). Dengue vaccine: an update. Expert Rev. Anti. Infect. Ther. 38, 178-185.

Idris, F., Ting, D. H. R., and Alonso, S. (2021). An update on dengue vaccine development, challenges, and future perspectives. Expert Opin. Drug Discov. 16, 47-58. doi: 10.1080/17460441.2020.1811675

Ishikawa, H., Ma, Z., and Barber, G. N. (2009). STING regulates intracellular DNAmediated, type I interferon-dependent innate immunity. Nature 461, 788-792. doi: $10.1038 /$ nature 08476

Jiang, L., Lu, C., and Sun, Q. (2021). Tree shrew as a new animal model for the study of dengue virus. Front. Immunol. 12:621164. doi: 10.3389/fimmu.2021.62 1164

Jones, M., Davidson, A., Hibbert, L., Gruenwald, P., Schlaak, J., Ball, S., et al. (2005). Dengue virus inhibits alpha interferon signaling by reducing STAT2 expression. J. Virol. 79, 5414-5420. doi: 10.1128/jvi.79.9.5414-5420.2005

Kallas, E. G., Precioso, A. R., Palacios, R., Thome, B., Braga, P. E., Vanni, T., et al. (2020). Safety and immunogenicity of the tetravalent, live-attenuated dengue vaccine Butantan-DV in adults in Brazil: a two-step, double-blind, randomised placebo-controlled phase 2 trial. Lancet Infect. Dis. 20, 839-850.

Katzelnick, L. C., Gresh, L., Halloran, M. E., Mercado, J. C., Kuan, G., Gordon, A., et al. (2017). Antibody-dependent enhancement of severe dengue disease in humans. Science 358, 929-932. doi: 10.1126/science.aan6836

Kawai, T., and Akira, S. (2011). Toll-like receptors and their crosstalk with other innate receptors in infection and immunity. Immunity 34, 637-650. doi: 10. 1016/j.immuni.2011.05.006

Kayesh, M. E. H., Hashem, M. A., Kitab, B., and Tsukiyama-Kohara, K. (2019). Pathogenesis and immune response caused by vector-borne and other viral infections in a tupaia model. Microorganisms 7:686. doi: 10.3390/ microorganisms7120686

Kayesh, M. E. H., Kitab, B., Sanada, T., Hayasaka, D., Morita, K., Kohara, M., et al. (2017). Susceptibility and initial immune response of Tupaia belangeri cells to dengue virus infection. Infect. Genet. Evol. 51, 203-210. doi: 10.1016/j.meegid. 2017.04.003

King, C. A., Wegman, A. D., and Endy, T. P. (2020). Mobilization and activation of the innate immune response to dengue virus. Front. Cell Infect. Microbiol. 10:574417. doi: 10.3389/fcimb.2020.574417

Kirkpatrick, B. D., Durbin, A. P., Pierce, K. K., Carmolli, M. P., Tibery, C. M., Grier, P. L., et al. (2015). Robust and balanced immune responses to all 4 dengue virus serotypes following administration of a single dose of a live attenuated tetravalent dengue vaccine to healthy. Flavivirus-Naive Adults. J. Infect. Dis. 212, 702-710. doi: 10.1093/infdis/jiv082

Kirkpatrick, B. D., Whitehead, S. S., Pierce, K. K., Tibery, C. M., Grier, P. L., Hynes, N. A., et al. (2016). The live attenuated dengue vaccine TV003 elicits complete protection against dengue in a human challenge model. Sci. Transl. Med. 8:330ra336.

Kittayapong, P., Olanratmanee, P., Maskhao, P., Byass, P., Logan, J., Tozan, Y., et al. (2017). Mitigating diseases transmitted by aedes mosquitoes: a clusterrandomised trial of permethrin-impregnated school uniforms. PLoS Negl. Trop. Dis, 11:e0005197. doi: 10.1371/journal.pntd.0005197

Kuhn, R. J., Zhang, W., Rossmann, M. G., Pletnev, S. V., Corver, J., Lenches, E., et al. (2002). Structure of dengue virus: implications for flavivirus organization, maturation, and fusion. Cell 108, 717-725.

Kumar, S., Sunagar, R., and Gosselin, E. (2019). Bacterial protein toll-like-receptor agonists: a novel perspective on vaccine adjuvants. Front. Immunol. 10:1144. doi: $10.3389 /$ fimmu.2019.01144 
Lai, J. H., Wang, M. Y., Huang, C. Y., Wu, C. H., Hung, L. F., Yang, C. Y., et al. (2018). Infection with the dengue RNA virus activates TLR9 signaling in human dendritic cells. EMBO Rep. 19:46182.

Lambrechts, L., Scott, T. W., and Gubler, D. J. (2010). Consequences of the expanding global distribution of Aedes albopictus for dengue virus transmission. PLoS Negl. Trop. Dis. 4:e646. doi: 10.1371/journal.pntd.0000646

Li, P., Jin, Y., Qi, F., Wu, F., Luo, S., Cheng, Y., et al. (2018). SIRT6 acts as a negative regulator in dengue virus-induced inflammatory response by targeting the DNA binding domain of NF-kappaB p65. Front. Cell Infect. Microbiol. 8:113. doi: $10.3389 /$ fcimb. 2018.00113

Liang, Z., Wu, S., Li, Y., He, L., Wu, M., Jiang, L., et al. (2011). Activation of Toll-like receptor 3 impairs the dengue virus serotype 2 replication through induction of IFN-beta in cultured hepatoma cells. PLoS One 6:e23346. doi: 10.1371/journal.pone.0023346

Lopez-Medina, E., Biswal, S., Saez-Llorens, X., Borja-Tabora, C., Bravo, L., Sirivichayakul, C., et al. (2020*). Efficacy of a dengue vaccine candidate (TAK$003)$ in healthy children and adolescents two years after vaccination. J. Infect. Dis. jiaa761.

Malavige, G. N., Jeewandara, C., and Ogg, G. S. (2020). Dysfunctional innate immune responses and severe dengue. Front. Cell Infect. Microbiol. 10:590004. doi: $10.3389 /$ fcimb.2020.590004

Martinez, D. R., Metz, S. W., and Baric, R. S. (2021). Dengue vaccines: the promise and pitfalls of antibody-mediated protection. Cell Host Microbe 29, 13-22. doi: 10.1016/j.chom.2020.12.011

Martinez-Moreno, J., Hernandez, J. C., and Urcuqui-Inchima, S. (2020). Effect of high doses of vitamin D supplementation on dengue virus replication, Toll-like receptor expression, and cytokine profiles on dendritic cells. Mol. Cell Biochem. 464, 169-180. doi: 10.1007/s11010-019-03658-w

Mathew, A. (2018). Defining the role of NK cells during dengue virus infection. Immunology 154, 557-562. doi: 10.1111/imm.12928

Mazzon, M., Jones, M., Davidson, A., Chain, B., and Jacobs, M. (2009). Dengue virus NS5 inhibits interferon-alpha signaling by blocking signal transducer and activator of transcription 2 phosphorylation. J. Infect. Dis. 200, 1261-1270. doi: $10.1086 / 605847$

McNab, F., Mayer-Barber, K., Sher, A., Wack, A., and O'garra, A. (2015). Type I interferons in infectious disease. Nat. Rev. Immunol. 15, 87-103. doi: 10.1038/ nri3787

Modhiran, N., Kalayanarooj, S., and Ubol, S. (2010). Subversion of innate defenses by the interplay between DENV and pre-existing enhancing antibodies: TLRs signaling collapse. PLoS Negl. Trop. Dis. 4:e924. doi: 10.1371/journal.pntd. 0000924

Modhiran, N., Watterson, D., Blumenthal, A., Baxter, A. G., Young, P. R., and Stacey, K. J. (2017). Dengue virus NS1 protein activates immune cells via TLR4 but not TLR2 or TLR6. Immunol. Cell Biol. 95, 491-495. doi: 10.1038/icb.2017.5

Modhiran, N., Watterson, D., Muller, D. A., Panetta, A. K., Sester, D. P., Liu, L., et al. (2015). Dengue virus NS1 protein activates cells via Toll-like receptor 4 and disrupts endothelial cell monolayer integrity. Sci. Transl. Med. 7:304ra142. doi: $10.1126 /$ scitranslmed.aaa3863

Morrison, J., Laurent-Rolle, M., Maestre, A. M., Rajsbaum, R., Pisanelli, G., Simon, V., et al. (2013). Dengue virus co-opts UBR4 to degrade STAT2 and antagonize type I interferon signaling. PLoS Pathog. 9:e1003265. doi: 10.1371/journal.ppat. 1003265

Moser, B. A., Steinhardt, R. C., Escalante-Buendia, Y., Boltz, D. A., Barker, K. M., Cassaidy, B. J., et al. (2020). ). Increased vaccine tolerability and protection via NF-kappaB modulation. Sci. Adv. 6:eaaz8700. doi: 10.1126/sciadv.aaz8700

Munoz-Jordan, J. L., Sanchez-Burgos, G. G., Laurent-Rolle, M., and Garcia-Sastre, A. (2003). Inhibition of interferon signaling by dengue virus. Proc. Natl. Acad. Sci. U.S.A. 100, 14333-14338.

Murphy, B. R., and Whitehead, S. S. (2011). Immune response to dengue virus and prospects for a vaccine. Annu. Rev. Immunol. 29, 587-619. doi: 10.1146/ annurev-immunol-031210-101315

Murphy Schafer, A. R., Smith, J. L., Pryke, K. M., Defilippis, V. R., and Hirsch, A. J. (2020). The E3 ubiquitin ligase SIAH1 targets MyD88 for proteasomal degradation during dengue virus infection. Front. Microbiol. 11:24. doi: 10. 3389/fmicb.2020.00024

Nasirudeen, A. M., Wong, H. H., Thien, P., Xu, S., Lam, K. P., and Liu, D. X. (2011). RIG-I, MDA5 and TLR3 synergistically play an important role in restriction of dengue virus infection. PLoS Negl. Trop. Dis. 5:e926. doi: 10.1371/journal.pntd. 0000926

Navarro-Sanchez, E., Despres, P., and Cedillo-Barron, L. (2005). Innate immune responses to dengue virus. Arch. Med. Res. 36, 425-435. doi: 10.1016/j.arcmed. 2005.04.007

Netea, M. G., Dominguez-Andres, J., Barreiro, L. B., Chavakis, T., Divangahi, M., Fuchs, E., et al. (2020). Defining trained immunity and its role in health and disease. Nat. Rev. Immunol. 20, 375-388. doi: 10.1038/s41577-020-0285-6

Netea, M. G., Joosten, L. A., Latz, E., Mills, K. H., Natoli, G., Stunnenberg, H. G., et al. (2016). Trained immunity: a program of innate immune memory in health and disease. Science 352:aaf1098. doi: 10.1126/science.aaf1098

Nivarthi, U. K., Swanstrom, J., Delacruz, M. J., Patel, B., Durbin, A. P., Whitehead, S. S., et al. (2021). A tetravalent live attenuated dengue virus vaccine stimulates balanced immunity to multiple serotypes in humans. Nat. Commun. 12:1102.

Osorio, J. E., Velez, I. D., Thomson, C., Lopez, L., Jimenez, A., Haller, A. A., et al. (2014). Safety and immunogenicity of a recombinant live attenuated tetravalent dengue vaccine (DENVax) in flavivirus-naive healthy adults in Colombia: a randomised, placebo-controlled, phase 1 study. Lancet Infect. Dis. 14, 830-838. doi: 10.1016/s1473-3099(14)70811-4

Osorio, J. E., Wallace, D., and Stinchcomb, D. T. (2016). A recombinant, chimeric tetravalent dengue vaccine candidate based on a dengue virus serotype 2 backbone. Expert Rev. Vaccines 15, 497-508. doi: 10.1586/14760584.2016. 1128328

Owen, A. M., Fults, J. B., Patil, N. K., Hernandez, A., and Bohannon, J. K. (2020). TLR agonists as mediators of trained immunity: mechanistic insight and immunotherapeutic potential to combat infection. Front. Immunol. 11:622614. doi: 10.3389/fimmu.2020.622614

Ozato, K., Tsujimura, H., and Tamura, T. (2002*). Toll-like receptor signaling and regulation of cytokine gene expression in the immune system. Biotechniques (Suppl.), 66-68,70,72assim.

Palma-Ocampo, H. K., Flores-Alonso, J. C., Vallejo-Ruiz, V., Reyes-Leyva, J., Flores-Mendoza, L., Herrera-Camacho, I., et al. (2015). Interferon lambda inhibits dengue virus replication in epithelial cells. Virol. J. 12:150.

Parthasarathy, D., Madhuravasal, J. K., Jayavel, P., Kulandai, L. T., Narahari Rao, M. H., and Jambulingam, M. (2018). Expression analysis of toll-like receptors of Dengue-infected cornea by real-time polymerase chain reaction. Inflamm. Res. 67, 555-558. doi: 10.1007/s00011-018-1148-5

Pinheiro-Michelsen, J. R., Souza, R., Santana, I. V. R., Da Silva, P. S., Mendez, E. C., Luiz, W. B., et al. (2020). Anti-dengue vaccines: from development to clinical trials. Front. Immunol. 11:1252. doi: 10.3389/fimmu.2020.01252

Pulendran, B., S Arunachalam, P., and O'hagan, D. T. (2021). Emerging concepts in the science of vaccine adjuvants. Nat. Rev. Drug. Discov. 20, 454-475. doi: 10.1038/s41573-021-00163-y

Quintin, J., Cheng, S. C., Van Der Meer, J. W., and Netea, M. G. (2014). Innate immune memory: towards a better understanding of host defense mechanisms. Curr. Opin. Immunol. 29, 1-7. doi: 10.1016/j.coi.2014.02.006

Quirino-Teixeira, A. C., Rozini, S. V., Barbosa-Lima, G., Coelho, D. R., Carneiro, P. H., Mohana-Borges, R., et al. (2020). Inflammatory signaling in dengueinfected platelets requires translation and secretion of nonstructural protein 1. Blood Adv. 4, 2018-2031. doi: 10.1182/bloodadvances.2019001169

Rahman, M. M., and McFadden, G. (2011). Modulation of NF-kappaB signalling by microbial pathogens. Nat. Rev. Microbiol. 9, 291-306. doi: 10.1038/ nrmicro2539

Rathore, A. P. S., and St John, A. L. (2018). Immune responses to dengue virus in the skin. Open Biol. 8:180087. doi: 10.1098/rsob.180087

Reynales, H., Carrasquilla, G., Zambrano, B., Cortes, S. M., Machabert, T., Jing, J., et al. (2020). Secondary analysis of the efficacy and safety trial data of the tetravalent dengue vaccine in children and adolescents in Colombia. Pediatr. Infect. Dis. J. 39, e30-e36.

Ritchie, S. A. (2018). Wolbachia and the near cessation of dengue outbreaks in Northern Australia despite continued dengue importations via travellers. J. Travel. Med. 25:tay084.

Rodriguez-Madoz, J. R., Belicha-Villanueva, A., Bernal-Rubio, D., Ashour, J., Ayllon, J., and Fernandez-Sesma, A. (2010a). Inhibition of the type I interferon response in human dendritic cells by dengue virus infection requires a catalytically active NS2B3 complex. J. Virol. 84, 9760-9774. doi: 10.1128/jvi. 01051-10 
Rodriguez-Madoz, J. R., Bernal-Rubio, D., Kaminski, D., Boyd, K., and FernandezSesma, A. (2010b). Dengue virus inhibits the production of type I interferon in primary human dendritic cells. J. Virol. 84, 4845-4850. doi: 10.1128/jvi.025 14-09

Roth, C., Cantaert, T., Colas, C., Prot, M., Casademont, I., Levillayer, L., et al. (2019). A modified mRNA vaccine targeting immunodominant NS Epitopes protects against dengue virus infection in HLA Class I transgenic mice. Front. Immunol. 10:1424. doi: 10.3389/fimmu.2019.01424

Rupp, R., Luckasen, G. J., Kirstein, J. L., Osorio, J. E., Santangelo, J. D., Raanan, M., et al. (2015). Safety and immunogenicity of different doses and schedules of a live attenuated tetravalent dengue vaccine (TDV) in healthy adults: a Phase $1 \mathrm{~b}$ randomized study. Vaccine 33, 6351-6359. doi: 10.1016/j.vaccine.2015. 09.008

Saez-Llorens, X., Tricou, V., Yu, D., Rivera, L., Jimeno, J., Villarreal, A. C., et al. (2018). Immunogenicity and safety of one versus two doses of tetravalent dengue vaccine in healthy children aged 2-17 years in Asia and Latin America: 18-month interim data from a phase 2 , randomised, placebo-controlled study. Lancet Infect Dis. 18, 162-170. doi: 10.1016/s1473-3099(17)30632-1

Salaun, B., Romero, P., and Lebecque, S. (2007). Toll-like receptors' two-edged sword: when immunity meets apoptosis. Eur. J. Immunol. 37, 3311-3318. doi: 10.1002/eji.200737744

Sanapala, P., and Pola, S. (2020). Role of Cytokines in Infectious Viral Disease. Singapore: Springer.

Sanchez-Ramon, S., Conejero, L., Netea, M. G., Sancho, D., Palomares, O., and Subiza, J. L. (2018). Trained immunity-based vaccines: a new paradigm for the development of broad-spectrum anti-infectious formulations. Front. Immunol. 9:2936. doi: 10.3389/fimmu.2018.02936

Sariol, C. A., Martinez, M. I., Rivera, F., Rodriguez, I. V., Pantoja, P., Abel, K., et al. (2011). Decreased dengue replication and an increased anti-viral humoral response with the use of combined Toll-like receptor 3 and $7 / 8$ agonists in macaques. PLoS One 6:e19323. doi: 10.1371/journal.pone.0019323

Scherwitzl, I., Mongkolsapaja, J., and Screaton, G. (2017). Recent advances in human flavivirus vaccines. Curr. Opin. Virol. 23, 95-101. doi: 10.1016/j.coviro. 2017.04.002

Schnare, M., Barton, G. M., Holt, A. C., Takeda, K., Akira, S., and Medzhitov, R. (2001). Toll-like receptors control activation of adaptive immune responses. Nat. Immunol. 2, 947-950. doi: 10.1038/ni712

Sengupta, S., Mukherjee, S., Bhattacharya, N., and Tripathi, A. (2021*). Differential genotypic signatures of Toll-like receptor polymorphisms among denguechikungunya mono- and co-infected Eastern Indian patients. Eur. J. Clin. Microbiol. Infect. Dis.

Sharma, S., Singh, S. K., Kakkar, K., Nyari, N., Dhole, T. N., Kashyap, R., et al. (2016). Analysis of TLR4 (Asp299Gly and Thr399Ile) gene polymorphisms and mRNA level in patients with dengue infection: a case-control study. Infect. Genet. Evol. 43, 412-417. doi: 10.1016/j.meegid.2016.06.027

Simmons, C. P., Farrar, J. J., Nguyen, V. V., and Wills, B. (2012). Dengue. N. Engl. J. Med. 366, 1423-1432.

Sirivichayakul, C., Barranco-Santana, E. A., Esquilin-Rivera, I., Oh, H. M., Raanan, M., Sariol, C. A., et al. (2016). Safety and immunogenicity of a tetravalent dengue vaccine candidate in healthy children and adults in dengue-endemic regions: a randomized. Placebo-Controlled Phase 2 Study. J. Infect. Dis. 213, 1562-1572. doi: 10.1093/infdis/jiv762

Sridhar, S., Luedtke, A., Langevin, E., Zhu, M., Bonaparte, M., Machabert, T., et al. (2018). Effect of dengue serostatus on dengue vaccine safety and efficacy. N. Engl. J. Med. 379, 327-340. doi: 10.1056/nejmoa1800820

Srikiatkhachorn, A. (2009). Plasma leakage in dengue haemorrhagic fever. Thromb. Haemost. 102, 1042-1049. doi: 10.1160/th09-03-0208

Srivastava, S., Chaudhary, N., Ojha, A., Guchhait, P., and Patel, A. K. (2021). Signal transducer and activator of transcription 3 (STAT3) acts as a proviral factor for dengue virus propagation. Virus Res. 300:198436. doi: 10.1016/j.virusres.2021. 198436

Stabell, A. C., Meyerson, N. R., Gullberg, R. C., Gilchrist, A. R., Webb, K. J., Old, W. M., et al. (2018). Dengue viruses cleave STING in humans but not in nonhuman primates, their presumed natural reservoir. eLife 7:e31919.

Struchiner, C. J., Rocklov, J., Wilder-Smith, A., and Massad, E. (2015). Increasing dengue incidence in singapore over the past 40 years: population growth, climate and mobility. PLoS One 10:e0136286. doi: 10.1371/journal.pone. 0136286
Su, C. I., Kao, Y. T., Chang, C. C., Chang, Y., Ho, T. S., Sun, H. S., et al. (2020). DNA-induced 2'3'-cGAMP enhances haplotype-specific human STING cleavage by dengue protease. Proc. Natl. Acad. Sci. U.S.A. 117, 15947-15954. doi: 10.1073/pnas.1922243117

Sun, B., Sundstrom, K. B., Chew, J. J., Bist, P., Gan, E. S., Tan, H. C., et al. (2017). Dengue virus activates cGAS through the release of mitochondrial DNA. Sci. Rep. 7:3594.

Sun, P., Fernandez, S., Marovich, M. A., Palmer, D. R., Celluzzi, C. M., Boonnak, K., et al. (2009). Functional characterization of ex vivo blood myeloid and plasmacytoid dendritic cells after infection with dengue virus. Virology 383, 207-215. doi: 10.1016/j.virol.2008.10.022

Tian, H., Sun, Z., Faria, N. R., Yang, J., Cazelles, B., Huang, S., et al. (2017). Increasing airline travel may facilitate co-circulation of multiple dengue virus serotypes in Asia. PLoS Negl. Trop. Dis. 11:e0005694. doi: 10.1371/journal.pntd. 0005694

Tillu, H., Tripathy, A. S., Reshmi, P. V., and Cecilia, D. (2016). Altered profile of regulatory $\mathrm{T}$ cells and associated cytokines in mild and moderate dengue. Eur. J. Clin. Microbiol. Infect. Dis. 35, 453-461. doi: 10.1007/s10096-015-25 61-0

Torres, S., Hernandez, J. C., Giraldo, D., Arboleda, M., Rojas, M., Smit, J. M., et al. (2013). Differential expression of Toll-like receptors in dendritic cells of patients with dengue during early and late acute phases of the disease. PLoS Negl. Trop. Dis. 7:e2060. doi: 10.1371/journal.pntd.0002060

Tremblay, N., Freppel, W., Sow, A. A., and Chatel-Chaix, L. (2019). The interplay between dengue virus and the human innate immune system: a game of hide and seek. Vaccines 7:145. doi: 10.3390/vaccines7040145

Tricou, V., Low, J. G., Oh, H. M., Leo, Y. S., Kalimuddin, S., Wijaya, L., et al. (2020a). Safety and immunogenicity of a single dose of a tetravalent dengue vaccine with two different serotype- 2 potencies in adults in Singapore: a phase 2, double-blind, randomised, controlled trial. Vaccine 38, 1513-1519. doi: 10 . 1016/j.vaccine.2019.11.061

Tricou, V., Saez-Llorens, X., Yu, D., Rivera, L., Jimeno, J., Villarreal, A. C., et al. (2020b). Safety and immunogenicity of a tetravalent dengue vaccine in children aged 2-17 years: a randomised, placebo-controlled, phase 2 trial. Lancet 395, 1434-1443. doi: 10.1016/s0140-6736(20)30556-0

Tsai, Y. T., Chang, S. Y., Lee, C. N., and Kao, C. L. (2009). Human TLR3 recognizes dengue virus and modulates viral replication in vitro. Cell Microbiol. 11, 604-615. doi: 10.1111/j.1462-5822.2008.01277.x

Turner, M., Papadimitriou, A., Winkle, P., Segall, N., Levin, M., Doust, M., et al. (2020). Immunogenicity and safety of lyophilized and liquid dengue tetravalent vaccine candidate formulations in healthy adults: a randomized, phase 2 clinical trial. Hum. Vaccin. Immunother. 16, 2456-2464. doi: 10.1080/21645515.2020. 1727697

Uno, N., and Ross, T. M. (2018). Dengue virus and the host innate immune response. Emerg. Microbes Infect. 7:167.

Van Hoeven, N., Wiley, S., Gage, E., Fiore-Gartland, A., Granger, B., Gray, S., et al. (2018). A combination of TLR-4 agonist and saponin adjuvants increases antibody diversity and protective efficacy of a recombinant West Nile Virus antigen. NPJ Vaccines 3:39.

Villar, L., Dayan, G. H., Arredondo-Garcia, J. L., Rivera, D. M., Cunha, R., Deseda, C., et al. (2015). Efficacy of a tetravalent dengue vaccine in children in Latin America. N. Engl. J. Med. 372, 113-123.

Waickman, A. T., Friberg, H., Gargulak, M., Kong, A., Polhemus, M., Endy, T., et al. (2019). Assessing the diversity and stability of cellular immunity generated in response to the candidate live-attenuated dengue virus vaccine TAK-003. Front. Immunol. 10:1778. doi: 10.3389/fimmu.2019.01778

Warner, J. D., Irizarry-Caro, R. A., Bennion, B. G., Ai, T. L., Smith, A. M., Miner, C. A., et al. (2017). STING-associated vasculopathy develops independently of IRF3 in mice. J. Exp. Med. 214, 3279-3292. doi: 10.1084/jem.2017 1351

Weiskopf, D., Angelo, M. A., Bangs, D. J., Sidney, J., Paul, S., Peters, B., et al. (2015). The human CD8+ T cell responses induced by a live attenuated tetravalent dengue vaccine are directed against highly conserved epitopes. J. Virol. 89, 120-128. doi: 10.1128/jvi.02129-14

Whitehead, S. S. (2016). Development of TV003/TV005, a single dose, highly immunogenic live attenuated dengue vaccine; what makes this vaccine different from the Sanofi-Pasteur CYD vaccine? Expert Rev. Vaccines 15, 509-517. doi: $10.1586 / 14760584.2016 .1115727$ 
Whitehead, S. S., Durbin, A. P., Pierce, K. K., Elwood, D., Mcelvany, B. D., Fraser, E. A., et al. (2017). ). In a randomized trial, the live attenuated tetravalent dengue vaccine TV003 is well-tolerated and highly immunogenic in subjects with flavivirus exposure prior to vaccination. PLoS Negl. Trop. Dis. 11:e0005584. doi: 10.1371/journal.pntd.0005584

Wilder-Smith, A. (2020). Dengue vaccine development: status and future. Bundesgesundheitsblatt Gesundheitsforschung Gesundheitsschutz 63, 40-44. doi: 10.1007/s00103-019-03060-3

Wilder-Smith, A., Ooi, E. E., Vasudevan, S. G., and Gubler, D. J. (2010). Update on dengue: epidemiology, virus evolution, antiviral drugs, and vaccine development. Curr. Infect. Dis. Rep. 12, 157-164. doi: 10.1007/s11908-0100102-7

Wilder-Smith, A., Smith, P. G., Luo, R., Kelly-Cirino, C., Curry, D., Larson, H., et al. (2019). Pre-vaccination screening strategies for the use of the CYDTDV dengue vaccine: a meeting report. Vaccine 37, 5137-5146. doi: 10.1016/j. vaccine.2019.07.016

World Health Organization (WHO) (2020). Dengue and Severe Dengue. Avaliable online at: https://www.who.int/news-room/fact-sheets/detail/dengue-andsevere-dengue (accessed March 23, 2021).

Wu, S. J., Grouard-Vogel, G., Sun, W., Mascola, J. R., Brachtel, E., Putvatana, R., et al. (2000). Human skin Langerhans cells are targets of dengue virus infection. Nat. Med. 6, 816-820.

Xing, J., Zhang, A., Du, Y., Fang, M., Minze, L. J., Liu, Y. J., et al. (2021a). Identification of poly(ADP-ribose) polymerase 9 (PARP9) as a noncanonical sensor for RNA virus in dendritic cells. Nat. Commun. 12:2681.

Xing, J., Zhou, X., Fang, M., Zhang, E., Minze, L. J., and Zhang, Z. (2021b). DHX15 is required to control RNA virus-induced intestinal inflammation. Cell Rep. 35:109205. doi: 10.1016/j.celrep.2021.109205

Yacoub, S., Mongkolsapaya, J., and Screaton, G. (2013). The pathogenesis of dengue. Curr. Opin. Infect. Dis. 26, 284-289.

Ye, H., Duan, X., Yao, M., Kang, L., Li, Y., Li, S., et al. (2021). USP18 mediates interferon resistance of dengue virus infection. Front. Microbiol. 12:682380. doi: $10.3389 /$ fmicb. 2021.682380
Yokota, S., Okabayashi, T., and Fujii, N. (2010). The battle between virus and host: modulation of Toll-like receptor signaling pathways by virus infection. Mediators Inflamm. 2010:184328.

Yu, C. Y., Chang, T. H., Liang, J. J., Chiang, R. L., Lee, Y. L., Liao, C. L., et al. (2012). Dengue virus targets the adaptor protein MITA to subvert host innate immunity. PLoS Pathog. 8:e1002780. doi: 10.1371/journal.ppat.1002780

Zhang, Z., Yuan, B., Bao, M., Lu, N., Kim, T., and Liu, Y. J. (2011). The helicase DDX41 senses intracellular DNA mediated by the adaptor STING in dendritic cells. Nat. Immunol. 12, 959-965. doi: 10.1038/ni.2091

Zuniga, E. I., Macal, M., Lewis, G. M., and Harker, J. A. (2015). Innate and adaptive immune regulation during chronic viral infections. Annu. Rev. Virol. 2, 573-597. doi: 10.1146/annurev-virology-100114-055226

Zust, R., Toh, Y. X., Valdes, I., Cerny, D., Heinrich, J., Hermida, L., et al. (2014). Type I interferon signals in macrophages and dendritic cells control dengue virus infection: implications for a new mouse model to test dengue vaccines. J. Virol. 88, 7276-7285. doi: 10.1128/jvi.03827-13

Conflict of Interest: The authors declare that the research was conducted in the absence of any commercial or financial relationships that could be construed as a potential conflict of interest.

Publisher's Note: All claims expressed in this article are solely those of the authors and do not necessarily represent those of their affiliated organizations, or those of the publisher, the editors and the reviewers. Any product that may be evaluated in this article, or claim that may be made by its manufacturer, is not guaranteed or endorsed by the publisher.

Copyright (c) 2021 Kayesh, Kohara and Tsukiyama-Kohara. This is an open-access article distributed under the terms of the Creative Commons Attribution License (CC BY). The use, distribution or reproduction in other forums is permitted, provided the original author(s) and the copyright owner(s) are credited and that the original publication in this journal is cited, in accordance with accepted academic practice. No use, distribution or reproduction is permitted which does not comply with these terms. 